\title{
Investigation Effect of Type, Property and Dimension of Stiffener Perforated Steel Shear Wall
}

\section{Farhad Dehghan ${ }^{1 *}$ and Yousef Zandi ${ }^{2}$}

${ }^{1}$ Master of Structures Engineering, Department of Civil Engineering, Tabriz Branch, Islamic Azad University, Tabriz, Iran

${ }^{2}$ Assistant Professor of Tabriz Azad University, Department of Civil Engineering, Tabriz Branch, Islamic Azad University, Tabriz, Iran

\begin{abstract}
Steel plate shear wall (SPSW) according extra ductility and high strength and lateral stiffness and improved behavior in plastic stage recognized as a good lateral system for building structure, particularly as it interests with earthquake resistant design. Improvise of opening is one advantage of this system. The researchers on perforated steel plate shear wall have shown that the shear strength and stiffness of an un-stiffened steel shear wall decrease due to perforation of the infill plate. So stiffener leads to increasing stability of structural system of buckling and strength, lateral stiffness. To this research still plate shear wall with opening that can be of different material such as rebar, steel plate also effect of increase and decrease of steel plate section area and effect of its dimension studied. Analysis result was observed that applying steel plate with similar area, leads to more ultimate strength. In additionally ultimate strength increase when area increased. With comparing of result of stiffeners dimension due maximum ultimate shear strength. Finally suggest optimum aspect ratio $(\mathrm{b} / \mathrm{t})$.
\end{abstract}

Keywords: Steel shear wall; Steel plate stiffener; Shear strength; Stiffener dimension; Opening

\section{Introduction}

From the early 1970s steel plate shear wall (SPSW) is known as a reliable lateral load resisting system in the high building. This system is applied duo of ductility and high energy dissipation, and improvement behavior in the buckling and post-buckling and construction of new building and rehabilitation damaged structures. The recent researches on (SPSW) showed that this system in compare with moment from is economical and leads to decrease steel consumption. The behavior of steel plate shear wall (SPSW) appears to be similar to the behavior of the plate girder in which the beam, acts as stiffener of the girder, and column acts as flange of the girder, although columns appear to be much stiffer than plate girder flanges. One advantage of this system is feasibility improvise opening for passing utility, architectural purpose and/or structural reasons. Place of opening dissembled in structural design may lead to decrease of seismic structural performance.

At 1961, as Basler [1] demonstrated for plate girders, the postbuckling tension field action of (SPSW) can provide considerable strength, stiffen and ductility. Although some part of the plate buckles, the overall (SPSW) system remains stable during the cyclic loading. Takahashi [2] experiment steel shear wall with different arrangement of stiffener for improving behaviour of them and experiments have been carried out minimum requirement inertia moment of plate to prevent the general buckling and transfer it to local buckling under plates. Roberts and Sabouri [3] experimental effect of opening on the steel shear wall. Experimental results demonstrated, strength and stiffness of (SPSW) decrease when increase diameter of opening. Ghomi and Asad [4] studied experimental and numerical a beat steel plate shear wall with and without stiffener. They may frame single story and single bay as experimental sample and evaluated different parameters such as strength, stiffness and energy dissipation capacity. They carried out stiffener leads to increase by $26 \%$ in comparison to without stiffener. Also proposed stiffness of specimen with stiffener is $51 \%$ more than specimen without stiffener. However, difference with this strength was negligible. Alavi and Nateghi [5] investigate effect diagonal stiffener on central perforated steel shear wall. They assumed that stiffener opening due to nonlinear behaviour of perforated steel shear wall. For this purpose studied three samples in the experimental and numerical investigation. In first sample steel shear wall with opening and diagonal stiffener, in the second sample steel shear wall without opening diagonal stiffener and lastly third sample was an un-stiffened thin steel shear wall were evaluated. They have been carried out stiffener lead to improve of behaviour perforated steel wall. Chao et al. [6] investigated behaviour steel shear wall with stiffener and without stiffener in the frame at different connection, such as rigid, semi-rigid and hinged connection. They reported that ultimate capacity of rigid connection frame is $5 \%$ more than other case. Although were not appear difference between semi-rigid and pin connection. The recent investigations at diagonally stiffened steel shear walls have shown that the diagonal stiffener increase shear strength and improve cyclic behaviour of perforated (SPSW). Hence this study has focused the effect type of stiffener that can be different material such as rebar and steel plate with different yield stress and different aspect ratio dimension evaluated.

\section{Finite element Modelling and Verification}

Laboratory investigate was conducted on $1 / 2$ scaled single-story, single-bay specimens of diagonally stiffened an un-stiffened steel shear walls. At IIEES* Tehran Iran, Alavi and Nateghi scaled single-story specimen with around $2 \mathrm{~m}$ width and $1.5 \mathrm{~m}$ height of SPSW, were designed and fabricated for test program (Figure 1). The boundary elements were made of standard profile HEB160 and the infill steel plate thickness taken $1 \mathrm{~mm}$. full moment connections were provided at the beam-column joints by complete penetration groove welds.

*Corresponding author: Farhad Dehghan, Master of Structures Engineering Department of Civil Engineering, Tabriz Branch, Islamic Azad University, Tabriz, Iran, Tel: +98 937968 7892; E-mail: farhadcivil66@gmail.com

Received December 27, 2016; Accepted February 07, 2017; Published February 15, 2017

Citation: Dehghan F, Zandi Y (2017) Investigation Effect of Type, Property and Dimension of Stiffener Perforated Steel Shear Wall. J Steel Struct Constr 3: 127. doi: 10.4172/2472-0437.1000127

Copyright: (c) 2017 Dehghan F, et al. This is an open-access article distributed under the terms of the Creative Commons Attribution License, which permits unrestricted use, distribution, and reproduction in any medium, provided the original author and source are credited. 
Citation: Dehghan F, Zandi Y (2017) Investigation Effect of Type, Property and Dimension of Stiffener Perforated Steel Shear Wall. J Steel Struct Constr 3: 127. doi: 10.4172/2472-0437.1000127

Page 2 of 4

The specimens were stiffened with two-sided diagonal and edge was stiffeners plates $(40 \mathrm{~mm} \times 5 \mathrm{~mm})$ and also it was perforated in the center with circular opening that has $400 \mathrm{~mm}$ diameter (Figure 2). The modeling was performed using the purpose nonlinear finite element ABAQUS 6.14 software are suited for the solution of nonlinear problem as specimen (Figure 3).

Experimental specimens analysed the nonlinear response with pushover method and applied nonlinear behavior of steel material. According to nonlinear stress-strain curve beam column connection of model is rigid for beam column and infill plates, solid element are selected. For this purpose ten models analyzed that three models for comparison of material type effect, and seven models investigated about aspect ratio dimension of stiffener at perforated infill steel shear wall.

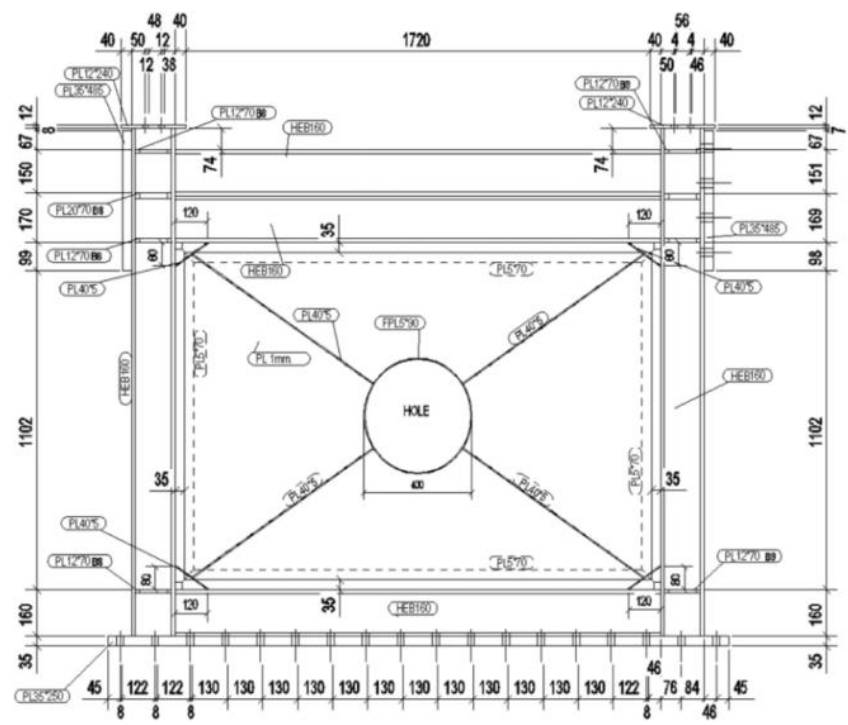

Figure 1: Specimen of steel shear wall with opening stiffener designed by ALAVI and C.

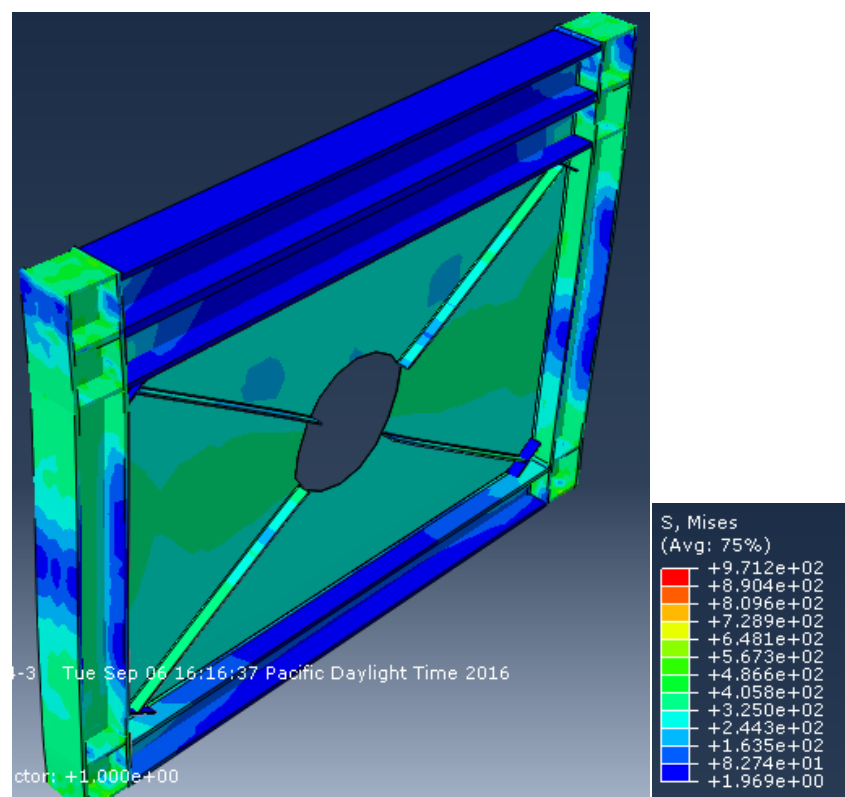

Figure 2: Specimen modelling at ABAQUS software.

\section{Numerical Modelling and Result Analyses}

Purpose of this research is to find the using pattern for steel shear wall with circular opening and with stiffener too. So dimensions of models have been based architectural requirement. For this aim verified by experimental specimen the bay of frame is $5.5 \mathrm{~m}$ and its height is 3.5 $\mathrm{m}$ and longitudinal of steel plate is $5.3 \mathrm{~m}$ and its height is $3.2 \mathrm{~m}$ and thickness of plate is $6 \mathrm{~mm}$. in addition a circular hole with dimension $1.2 \mathrm{~m}$ was perforated in the wall center. Stiffeners modelled of steel plate and rebar. Specifications of material were according Table 1.

To these research three models of steel shear wall with difference at stiffener type are evaluated. At first model for stiffener have been applied steel plate width $40 \mathrm{~mm}$ and its thickness $20 \mathrm{~mm}$ and steel property is ST37. At second and third models have been used rebar with quality A2 and A3, respectively. Diameter of rebar that selected similar section area with steel plate as stiffener applied. At (Figures 4-6), respectively all models are shown.

The results of their analyses presented in Table 2.

Seven models evaluated for comparison influence of stiffener dimension (width-to-thickness) ratio (b/t).the stiffener dimension

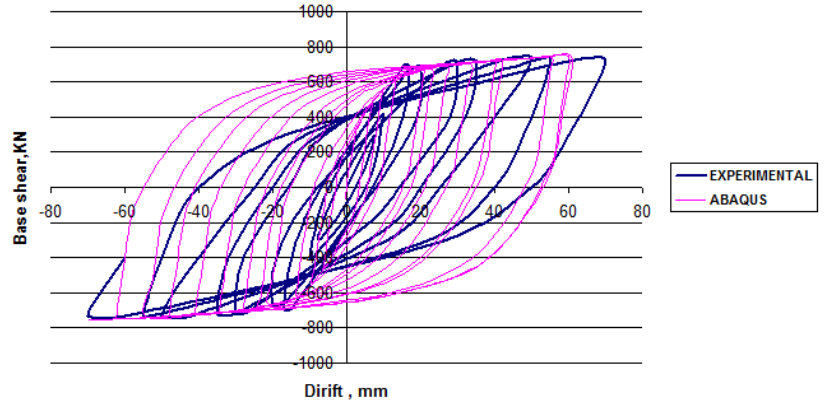

Figure 3: Comparison of experimental result and numerical result.

\begin{tabular}{|l|c|c|c|c|}
\hline $\begin{array}{l}\text { Steel } \\
\text { material }\end{array}$ & $\begin{array}{c}\text { Elastic modulus } \\
\text { (MPa) }\end{array}$ & $\begin{array}{c}\text { Static yield } \\
\text { (MPa) }\end{array}$ & $\begin{array}{c}\text { Static ultimate } \\
\text { (MPa) }\end{array}$ & $\begin{array}{c}\text { Ultimate strain } \\
\%\end{array}$ \\
\hline Steel ST37 & 204000 & 240 & 370 & 25 \\
\hline Rebar A2 & 200000 & 300 & 500 & 19 \\
\hline Rebar A3 & 200000 & 400 & 600 & 14 \\
\hline
\end{tabular}

Table 1: Specification of material for ABAQUS software.

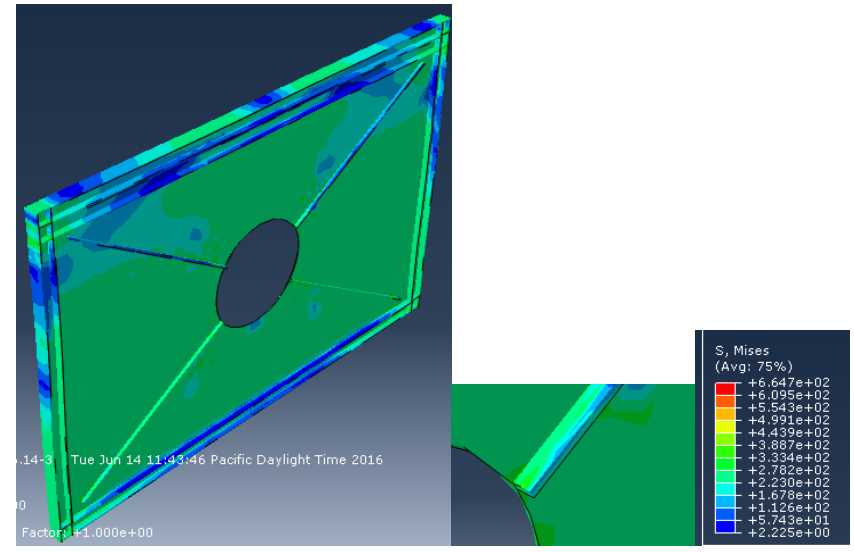

Figure 4: Using steel plate $20 \times 40$ as stiffener. 
Citation: Dehghan F, Zandi Y (2017) Investigation Effect of Type, Property and Dimension of Stiffener Perforated Steel Shear Wall. J Steel Struct Constr 3: 127. doi: 10.4172/2472-0437.1000127
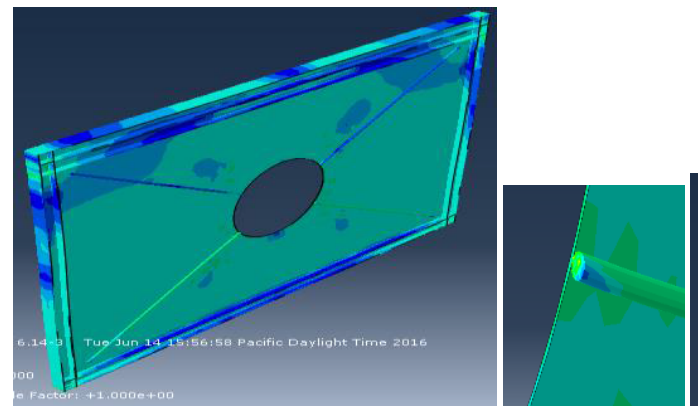

Figure 5: Using rebar A2 as stiffener.
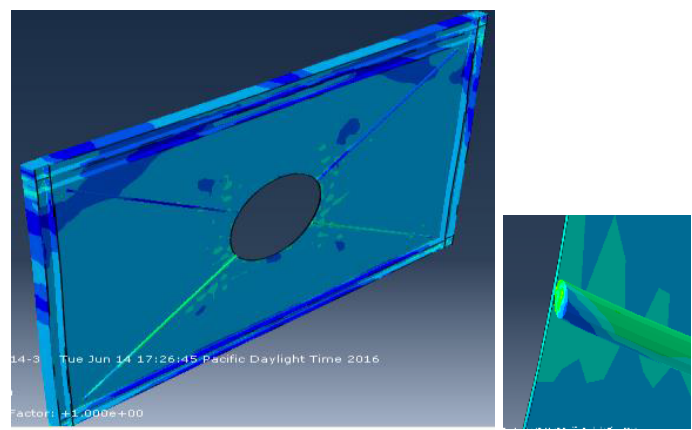

Figure 6: Using rebar $\mathrm{A} 3$ as stiffener.

\begin{tabular}{|l|c|c|}
\hline Stiffener type & $\begin{array}{c}\text { Compressive force } \\
\text { (KN) }\end{array}$ & $\begin{array}{c}\text { Tension force } \\
\text { (KN) }\end{array}$ \\
\hline Steel plate $20 \times 40$ & 3717 & 3710 \\
\hline Rebar A2 $(\mathrm{d}=32)$ & 3704 & 3674 \\
\hline Rebar A3 $(\mathrm{d}=32)$ & 3711 & 3697 \\
\hline
\end{tabular}

Table 2: Comparison of ultimate load with difference at stiffener material type.

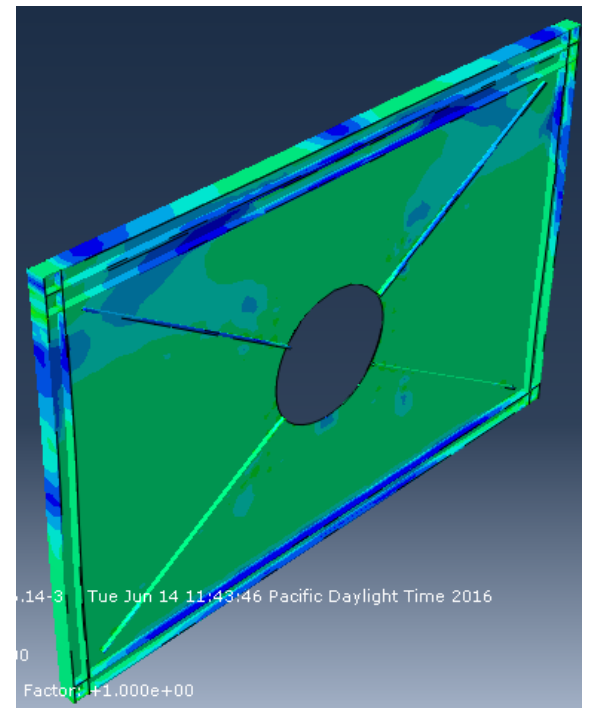

Figure 7: Stiffener $20 \times 60$

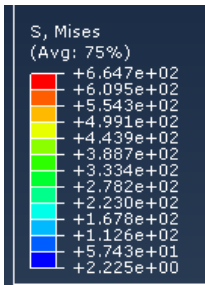

have selected at syntactic that width increasing to be step-by-step till influence due width growth to have been comparable.

Von-Mises stresses with difference at stiffener dimension of steel shear wall are shown in (Figures 7-10) for stiffener dimension $20 \times 40$,
$20 \times 80,20 \times 100,30 \times 60$, respectively.

As ultimate load of models shown in Table 3 and these values are comparable.

\section{Result and Discussion}

The ultimate strength obtained for steel plate stiffener is more than other stiffeners according Table 2 in so much modeling done syntactic that section area for all stiffener are similar, observed different at ultimate strength due geometric shape of section. As gyration radius of rectangular section is more than circular section. From this comparative, it is also observed the value of resistant force increase with gyration radius enhancement. In addition from the comparative, that is taken, ultimate strength of stiffener with A3 rebar is more than ultimate strength of A2 rebar. Because yield and ultimate stress at A3 rebar is more than $\mathrm{A} 2$ rebar. In other hand, is attributive ratio between value of yield- ultimate stresses and system strength value?

Table 3 shows that increasing section are of stiffener would lead to an increase in ultimate strength. It should be noted that this formula is not always right, for example at stiffener $20 \times 90$ is less than stiffener $30 \times 60$. Indeed, reasons of this problem maybe different of ratio

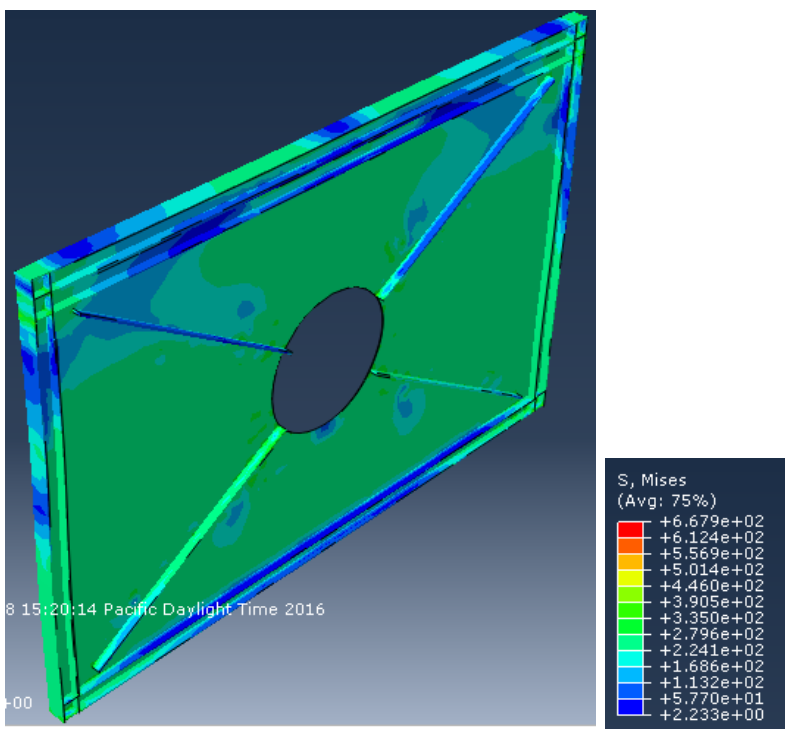

Figure 8: Stiffener $20 \times 80$.
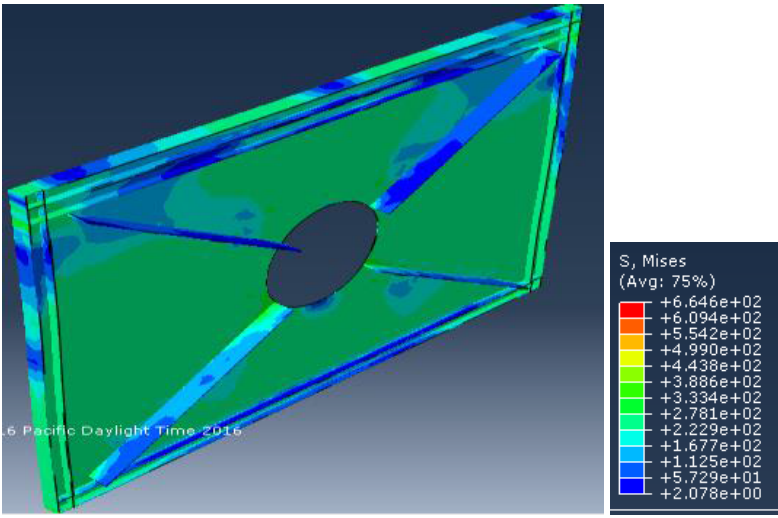

Figure 9: Stiffener $20 \times 100$. 
Citation: Dehghan F, Zandi Y (2017) Investigation Effect of Type, Property and Dimension of Stiffener Perforated Steel Shear Wall. J Steel Struct Constr 3: 127. doi: 10.4172/2472-0437.1000127

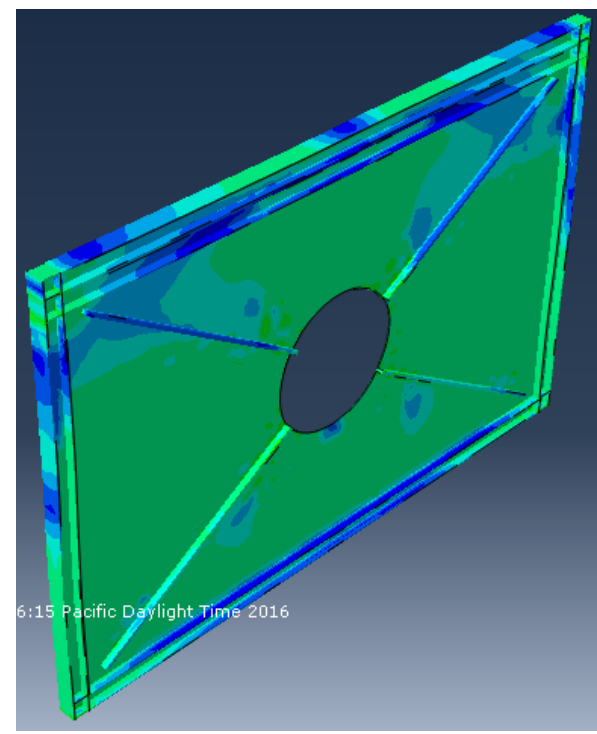

Figure 10: Stiffener $30 \times 60$.

\begin{tabular}{|c|c|c|}
\hline Stiffener dimension & Compressive force (KN) & Tension force (KN) \\
\hline $20 \times 40$ & 3717 & 3710 \\
\hline $20 \times 60$ & 3731 & 3727 \\
\hline $20 \times 80$ & 3742 & 3735 \\
\hline $20 \times 90$ & 3752 & 3748 \\
\hline $20 \times 100$ & 3732 & 3706 \\
\hline $20 \times 120$ & 3729 & 3702 \\
\hline $30 \times 60$ & 3762 & 3750 \\
\hline
\end{tabular}

Table 3: Ultimate load comparison with difference stiffener dimension.

$(\mathrm{b} / \mathrm{t})$. The analyse results showed that by increasing aspect ratio more than limiting value, ultimate strength reduced. It is seems, strength reduction due of local buckling at high aspect ratio probably. As this case at stiffener $20 \times 100$ and stiffener $20 \times 120$ are significant in comparison stiffener $20 \times 90$.

\section{Conclusion}

- The results showed that using the steel plate as stiffener instead of rebar would lead to an increase in ultimate strength.

- The numerical analyzes showed that by enhancement and ultimate stress of stiffener material, ultimate strength of system increased.

- Increasing section area of stiffener would lead to an increase in ultimate strength. Enhancement of section area should be syntactic that aspect ratio limited. Optimum value for aspect ratio is between 2 to 3 suggested.

- Using aspect ratio (b/t) more than 5 lead to local buckling of stiffener and decrease ultimate strength.

\section{References}

1. Basler K (1961) Strength of plate girders in shear, ASCE [J]. Journal of the Structural Division 87: 150-180

2. Takahashi Y (1973) Experimental Study on Thin Steel Shear Walls and Particular Steel Bracings under Alternative Horizontal Load. Preliminary Report IABSE Symposium on Resistance and Ultimate Deformability of Structures Acted on by Well Defined Repeated loads, Lisbon, Portugal, pp: 185-191.

3. Roberts TM, Ghomi SS (1992) Hysteretic Characteristics of Unstiffened Perforated Steel Plate Shear Panels. Thin Walled Structures 14: 139-151.

4. Ghomi SS, Asad RS (2012) Experimental and theoretical studies of steel shear walls with and without stiffeners. Journal of Constructional Steel Research 75: 152-159.

5. Alavi E, Nateghi F (2013) Experimental study on diagonally stiffened steel plate shear walls with central perforation. J Constr Steel Res 89: 9-20.

6. Chao HG, Hao JP, Liu YH (2015) Behavior of stiffened and unstiffened stee plate shear walls considering joint properties. J Thin-Walled Structures 97: 53-62. 